\title{
Polishing, Preparation and Patterning of Diamond for Device Applications
}

\author{
M-L. Hicks ${ }^{1}$, Alexander C. Pakpour-Tabrizi ${ }^{1}$, Richard B. Jackman ${ }^{1,2}$ \\ ${ }^{1}$ London Centre for Nanotechnolocy, University College London, \\ 17-19 Gordon Street, WC1H 0AH London, UK \\ ${ }^{2}$ Corresponding author: r.jackman@ucl.ac.uk
}

\begin{abstract}
Central to future electronic device developments in diamond is the provision of smooth, low defect density substrate materials. This review examines plasma treatments of diamond to enable smoothing of rough surfaces, the removal of damage created by various non-plasma polishing processes previously applied and for patterning into device structures. The favoured reported plasma treatments for surface smoothing are detailed. The characterisation, effectiveness and other fabrication considerations of each plasma process are discussed. Despite significant recent progress the processing technology associated with plasma-etching diamond remains immature when compared to those used for conventional semiconductor materials.

Keywords: synthetic diamond, etching, polishing, reactive ion etching, defect characterisation, surface characterisation.
\end{abstract}

\section{Introduction}

Diamond is a material with exceptional properties, showing promise for applications in power electronics, quantum technologies and biotechnology, to name a few. [1-5] Crucial to successfully producing diamond devices is achieving high quality epitaxial diamond growth, which in turn is reliant on the use of low defect substrates, and upon subsequent device fabrication.

Two categories of defects can pose a challenge in this context: bulk defects and polishing-induced damage. The latter is introduced during the polishing and smoothing of diamond chips in the form of dislocations; these are then able to propagate during epitaxial growth leading to poor crystalline quality in the epilayer. These defects can act as scattering centres and charge carrier traps which will compromise device performance. $[6,7]$

Polishing damage is thought to extend significantly below the surface of the diamond substrate, although few estimates or precise assessments are reported in the published literature and those that are range from hundreds of 
nanometers to 10 microns. [6, 8-10] A pre-growth treatment has therefore been suggested as a method for the removal of this region to improve the quality of the substrate and minimise defect propagation into subsequently grown diamond layers. Such an optimal treatment must fulfill a number of requirements: efficient material removal rate, polishing damage reduction and surface roughness reduction. Similarly fabrication methods needed for device realisation from the epitaxial layers must produce pre-defined patterns without impacting the quality of the diamond surface, and proceed with a practical rate.

This review examines the available scientific literature on diamond polishing and existing treatments - with an emphasis on plasma treatments in particular - to smooth the surface of substrates and remove polishing damage prior to epitaxial growth. The application and optimisation of such plasma treatments to patterning is also considered and the characterisation and effectiveness discussed.

\section{Diamond Polishing}

The art of polishing diamonds has been honed over centuries and is the cornerstone of the gem industry. The process has changed little from early descriptions from the late $18^{\text {th }}$ and early $19^{\text {th }}$ century and relies heavily on artisan skills and empirical knowledge. The diamond is placed on a metal wheel or scaife with a slurry consisting of small diamond grit (Figure 1). Pressure is applied to the diamond as the wheel turns and the friction with the grit abrades the surface of the diamond leading to the smoothing-polishing effect. $[7,11]$

Diamond is both extremely hard and brittle; the mechanisms at play during the polishing process are still poorly understood. Observations have highlighted crystallographic anisotropy of the diamond polishing process (Figures 2 and 3). When polished along the so-called "soft" direction crystal facets, i.e. the (100) where atomic density is less than for the say, (111), diamond is removed readily with little vibration and sound being produced during the process. The polishing by-products generally include $\mathrm{sp}^{1}$ and $\mathrm{sp}^{2}$ forms of carbon and an optically smooth polished surface is achieved. In contrast, in the "hard" direction, such as (111), the removal rate of diamond is lower, creating vibrations and noise due to the energetic nature of the process and the need to release excess energy. The by-products of the polishing can include $\mathrm{sp}^{3}$ forms of carbon and the surface usually shows signs of microfractures and cracking.

A number of models have been suggested to explain the wear anisotropy of diamond, however no single model seems to be currently accepted as proven in published literature. [11, 13] Although there are variations in the detail, it has been postulated that, when polished in the "soft" direction, the carbon bond is able to rehybridize to non-diamond forms of carbon, such as graphitic carbon, and thus be removed from the surface. A mechanical fracture mechanism is more likely to operate in the "hard" directions. The velocity and angle of the scaife process, amongst others, have also been suggested as contributing factors to the quality of the polishing. 


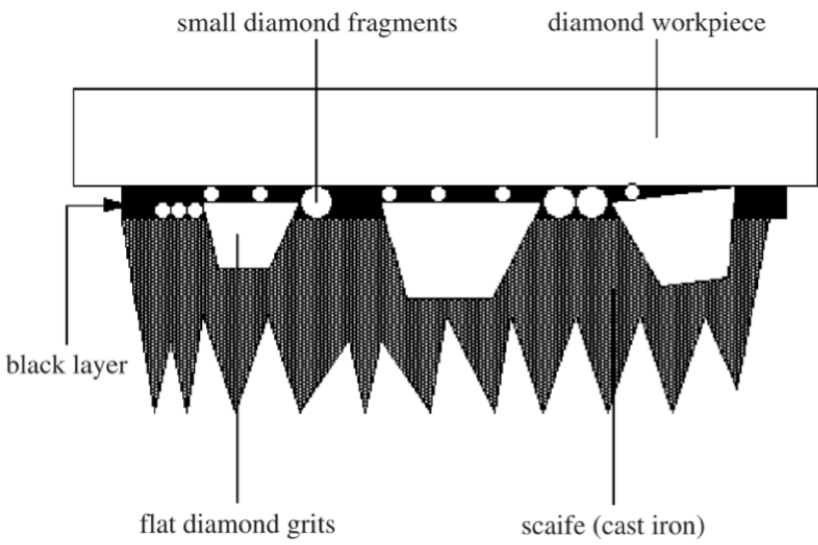

direction of rotation

Figure 1: Schematic of scaife polishing. The exact polishing mechanism is unconfirmed but it is suggested that the flat diamond grits behave like anvils for the small diamond fragments to apply pressure on the diamond workpiece. Taken from [11].

Lacking an agreed first principles understanding of the process, the success of this form of diamond polishing in achieving smoothed surfaces relies heavily upon the know-how of the diamond polisher and can vary greatly in quality.

When it comes to the use of diamond as an electronic material, the polishing process is of even greater importance than for non-technological applications such as within gemology, where an optically smooth polish finish suffices. Truly smooth surfaces, ideally atomically smooth, are necessary for the high quality homoepitaxial growth desired for electronic device fabrication. Diamond polishing using the process described above does not produce ideal substrates for this use. In fact, the polishing process introduces sub-surface mechanical damage. [6] Again, the mechanisms leading to and the extent of this damage are poorly understood. An increased density of dislocations in the vicinity of the surface is, however, reported, with the depth of the damage layer estimated to range from the nanometer scale to the tens of micrometers depending on the sample and process. [6, 8-10] These dislocations are able to travel through the material during subsequent epitaxial growth that is required for device fabrication and act as electronic traps and scattering centres, seriously degrading the performance of diamond devices fabricated from these layers.

To improve this position, novel polishing methods are in development with a view to enhance chemical polishing mechanisms over purely-mechanical. This is important as chemical processes impart little energy to the remaining diamond lattice when compared to physical abrasion and can therefore minimise the sub-surface damage produced and further reduce the achieved sur- 


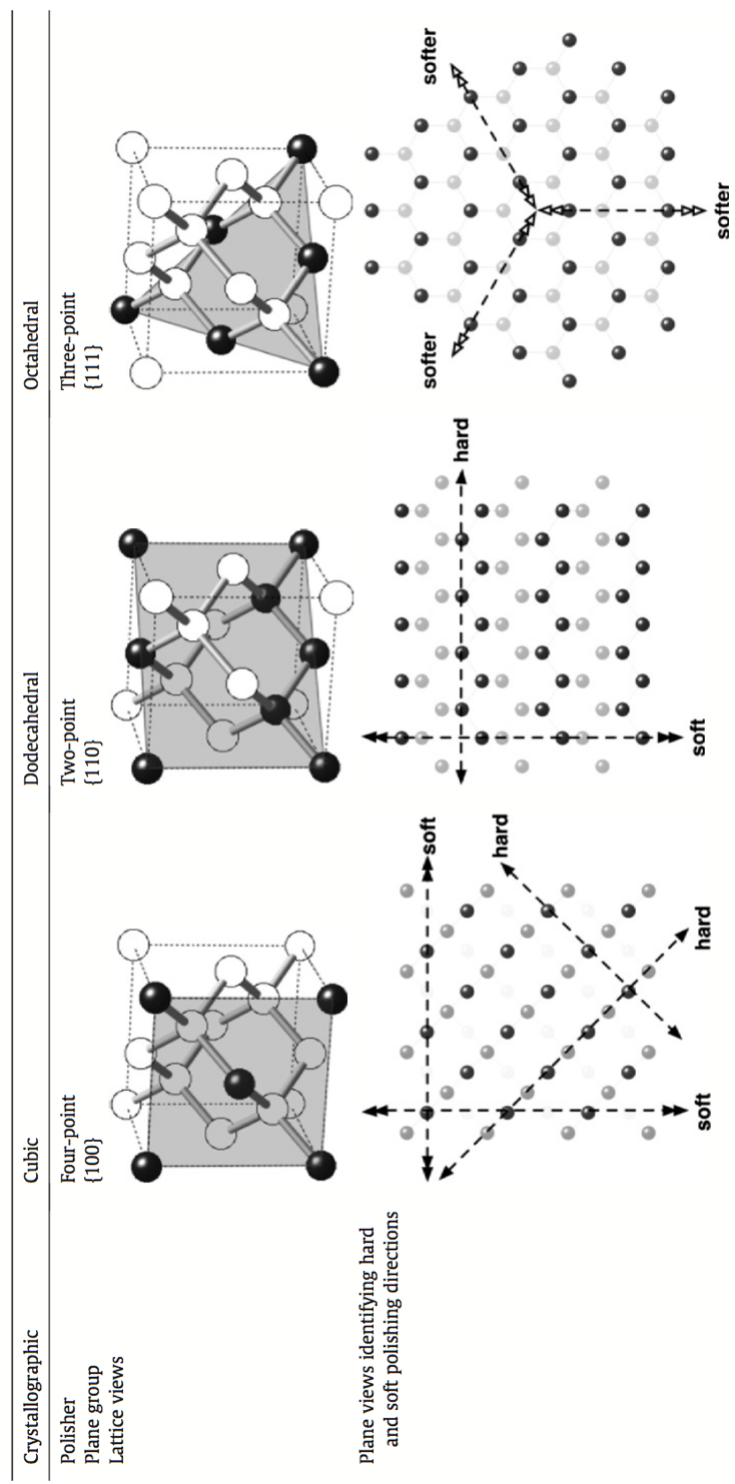

Figure 2: Diamond polishing: 'soft' and 'hard' directions for different crystal planes. The 'hard' direction is generally along the highest atom density direction of the given plane, whereas the 'soft' direction is along lower density directions. Taken from [7].

face roughness. Thomas et al. reported encouraging results on the use of a polyurethane/polyester cloth and silica colloid for polishing nanocrystalline diamond films (Figure 4). [14] Chemical mechanical polishing with an $\mathrm{SiO}_{2}$ wheel 


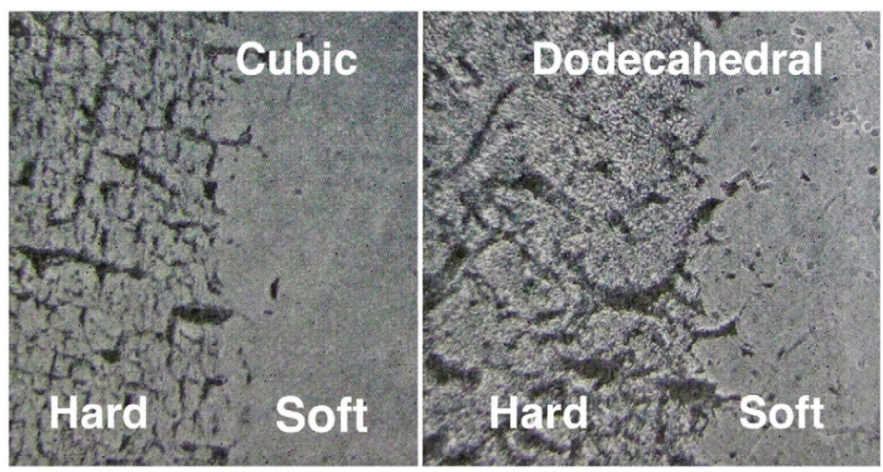

Figure 3: Surfaces of cubic (100) and dodecahedral (111) after polishing in the 'hard' and 'soft' directions. These SEM images illustrate the contrast in surface quality for different polishing directions: 'hard' polishing is accompanied by cracks and surface defects whereas a much smoother finish is achieved in the 'soft' direction. Taken from $[7,12]$.

has also been reported on single crystal diamond with promising results by Tatsumi et al. $[15,16]$ Yuan et al. proposed tribochemical polishing of polycrystalline diamond, suggesting a catalytic enhancement of the diamond-tographite conversion before mechanical removal of the graphitic material (Figure 5). [17] Polishing defects were however clearly visible on the Scanning Electron Microscopy (SEM) image of the surface. UV photochemically enhanced polishing (Figure 6) has also been investigated by Watanabe et al., achieving sub-nanometer roughness and reduced defect density. [18, 19] These techniques, although encouraging for the future of diamond polishing, are still at an early development stage, yet to be applied to single crystal diamond and, importantly, lacking in the subsequent characterisation of the sub-surface effects of the process.

\section{Diamond Etching for Surface Smoothing and Pre- Growth Treatment}

A number of different methods are reported in the literature for single crystal diamond surface etching and smoothing for pre-epitaxial growth treatment and for the removal of polishing damage. This review focuses on the most reported and relatively successful techniques - Reactive Ion Etching (RIE), including Electron Cyclotron Resonance etching (ECR-RIE) and especially Inductively Coupled Plasma etching (ICP-RIE) - but also considers wet etching, Focused Ion Beam (FIB) milling, Dressed Photon Phonon Etching (DPP) and the use of metal nanoparticle catalysts for diamond substrate surface treatment.

RIE is a dry etching method that utilizes an excited gas species or plasma to 


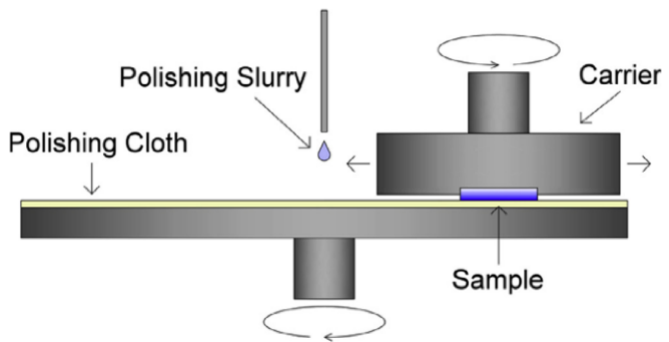

Figure 4: Schematic of chemical mechanical polishing on diamond with a cloth. The sample is held in place and rotated along the surface of the polishing cloth with a continuous feed of slurry to assist the removal of diamond material. Taken from [14].

perform a chemical and/or physical etch of the sample. Input power, in the form of an electrode bias with set radio frequency (RF), controls the ion density and energy within the plasma. RF is applied between a top electrode and the bottom electrode, usually where the sample is placed. ICP-RIE has an additional RF coil external to the chamber with the directly coupled RF electrodes. This $\mathrm{RF}$ is inductively coupled into the plasma and enables the separate control of ion energy and ion density, through individual manipulation of the direct RF and ICP powers respectively. This typically results in higher etch rates and more controlled and directional etching being achieved than the application of RF energy alone. For a general overview of RIE and ICP-RIE technologies the reader should consult [20]. ECR is used to produce high plasma densities, whilst maintaining low pressure and temperature conditions. For diamond, all three methods are reported in the literature using a range of gaseous etchant combinations. [21-23]

In addition to the use of conventional semiconductor cleanroom-based RIE tools, several reports have been made on the use of the microwave-plasmaenhanced chemical vapour deposition (MWPECVD) system used for film diamond growth to be subsequently deployed for the required etching steps. Initial attempts were made with hydrogen, oxygen and the combination of these two gases. $\mathrm{H}_{2} / \mathrm{O}_{2}$ is particularly interesting because this these gases are standard gases for microwave enhance chemical vapour deposition of diamond, meaning no modifications to the gas delivery system is needed. Diamond is notoriously hard to chemically etch with most chemical reagents due to its chemical inertness, but the presence of atomic $\mathrm{H}$ and $\mathrm{O}$ species formed by the microwave plasma leads it to readily react with both species through oxidation and hydrogen-assisted surface diffusion. Etch rates of the order of $10^{-2}-10^{-1}$ $\mu \mathrm{m} / \mathrm{min}$ have been reported. [24-26] Ivanov et al. observed a minimal change in sample roughness with a pure $\mathrm{H}_{2}$ plasma, maximum $0.1 \mathrm{~nm}$ or $+/-25 \%$. [27] This measurement was however taken in a pit-free area on samples with $10^{4}-10^{6}$ 

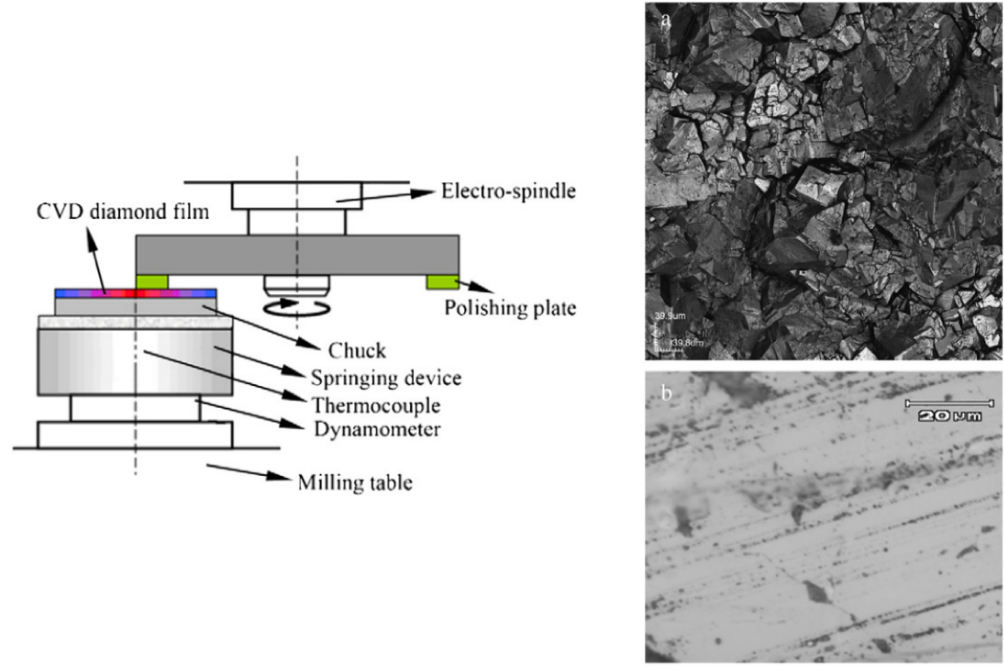

Figure 5: Schematic of tribochemical polishing and effect on diamond surface (SEM before (a) and after (b)). The diamond is polished by being pushed against a fast rotating metal plate, which generates enough friction to cause a thermochemical reaction. The surface of the diamond is smoothed (b compared to a), however defects (darker areas in b) are observed. Taken from [17].
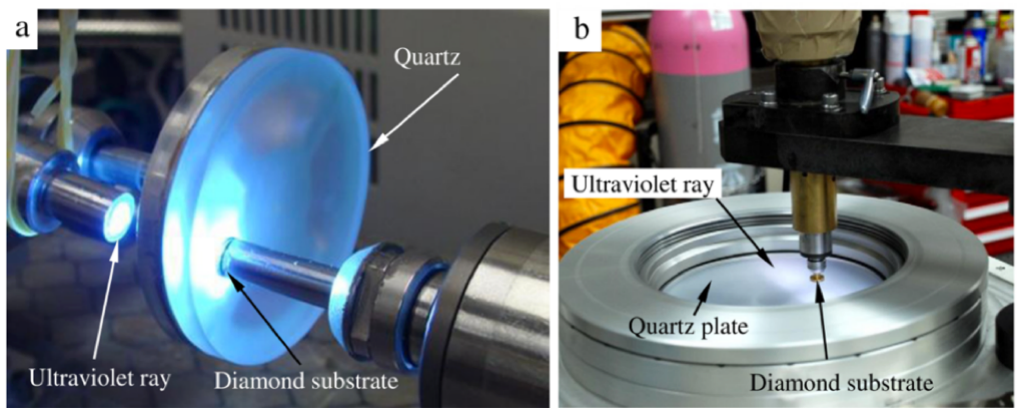

Figure 6: Illustration of UV photochemically enhanced polishing in the (a) horizontal and (b) vertical set up. UV light is used to oxidise the top atom layers of diamond, facilitating their subsequent mechanical removal. Taken from [18]. 
$\mathrm{cm}^{-2}$ etch pit density and 1-5 $\mu \mathrm{m}$ pit length, similar to those observed after etching in a $\mathrm{H}_{2} / \mathrm{O}_{2}$ plasma. Roughening of the surface is also reported for a pure $\mathrm{O}_{2}$ etch. [28]

All studies reported to have observed the formation of surface pits when etching with $\mathrm{O}_{2}, \mathrm{H}_{2}$ and $\mathrm{H}_{2} / \mathrm{O}_{2}$ plasmas (Figure 7 ). The differing atomic densities of the different crystallographic planes in diamond result in different oxidation rates; moreover, weaker $\mathrm{C}-\mathrm{C}$ bonds in the vicinity of defects are also more likely to react, resulting in a preferential etch and the formation of pyramid-shaped etch pits along the $\langle 110\rangle$. [26, 27, 29-32] The preferential nature of these etchants has led to their use in diamond defect studies, where they can highlight the location and density of pre-existing surface defects. This effect has also been exploited for anistropic, crystallographic, etching for the purposeful realisation of 3D diamond structures. [29, 33-35] Hausman et al. have reported the formation of so-called 'nano-grass' with $\mathrm{O}_{2}$ ICP RIE. [25] These vertical grass-like structures are most likely the result of micro-masking by small particles sputtered from a mask (used to selectively define etched areas on a chip) or a carrier wafer (onto which the relatively small diamond is mounted) and deposited on the diamond surface during the plasma etch. However, it is reported that smooth surfaces have been obtained by finding the optimal process temperature, reducing the process pressure and changing the ICP power whilst etching is occurring, but no quantitative surface roughness values were reported.
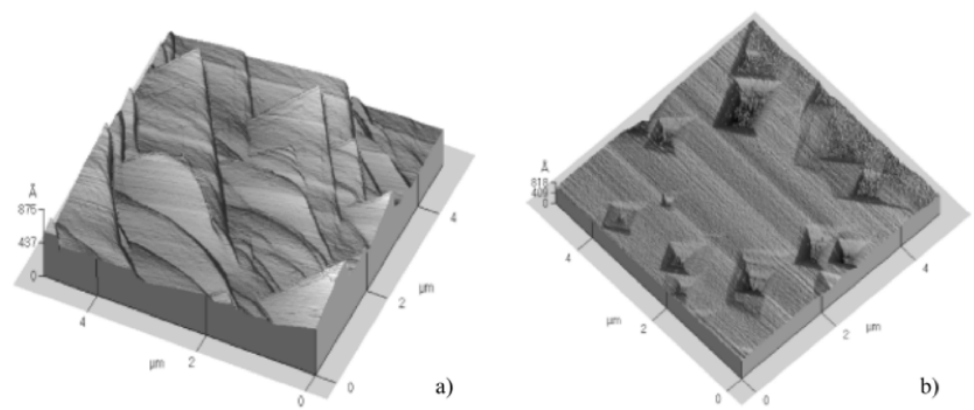

Figure 7: Illustration of etch pits observed after etching, in this case after 60 min (a) and 90 min (b) in $\mathrm{O}_{2} / \mathrm{H} 2$ plasma. Taken from [26].

In order to improve oxygen plasma etching, the introduction of a second gas, $\mathrm{CF}_{4}, \mathrm{SF}_{6}, \mathrm{SiCl}_{4}, \mathrm{Cl}_{2}$ or $\mathrm{CHF}_{3}$, to the process has been explored in order to attempt to reduce the effects of micro-masking. (Figure 8) [22, 24, 28, 36, 37] It is known that the RIE process can result in small particles sputtering from the mask and substrate holder and that these can be deposited onto the surface of the sample. These deposits act as 'micro-masks' producing nano-grass or whiskers on the surface of the diamond, as mentioned above. $\mathrm{CF}_{4}$ and $\mathrm{SF}_{6}$ etch silicon and other mask materials preferentially compared to diamond, and even small additions of these gases to the process have resulted in significant 
improvements in the surface roughness compared to pure $\mathrm{O}_{2}$ plasma etching. Ando et al., for example, report a reduction in mean roughness to $0.4 \mathrm{~nm}$ and an increased etch rate of $9.5 \mu \mathrm{m} / \mathrm{h}$ with a small addition of $\mathrm{CF}_{4}$ to the plasma. (Figure 9) [28] $\mathrm{SF}_{6}$ has a similar effect, reducing whisker formation, although Tran et al still report an increase in average surface roughness from $11.7 \mathrm{~nm}$ to $20.2 \mathrm{~nm}$ after etching. [22] The issue of preferential etching and pit formation is not addressed by the addition of these gases.
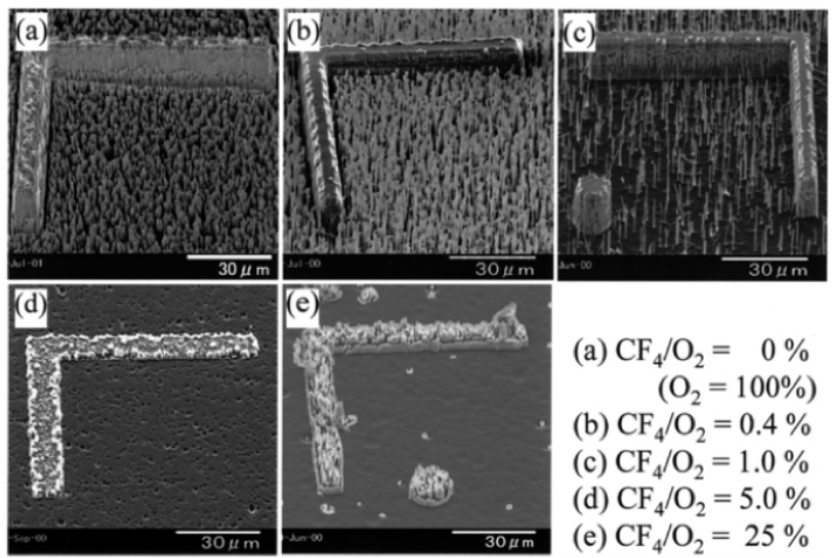
(a) $\mathrm{CF}_{4} / \mathrm{O}_{2}=0 \%$
$\left(\mathrm{O}_{2}=100 \%\right)$
(b) $\mathrm{CF}_{4} / \mathrm{O}_{2}=0.4 \%$
(c) $\mathrm{CF}_{4} / \mathrm{O}_{2}=1.0 \%$
(d) $\mathrm{CF}_{4} / \mathrm{O}_{2}=5.0 \%$
(e) $\mathrm{CF}_{4} / \mathrm{O}_{2}=25 \%$

Figure 8: Reduction of micro-masking with addition of $\mathrm{CF}_{4}$ to $\mathrm{O}_{2}$ plasma (SEM). Grass-like features are observed in images (a), (b) and (c) but their density reduces to near zero for $5 \% \mathrm{CF}_{4}$ as seen in (d) Taken from [28].

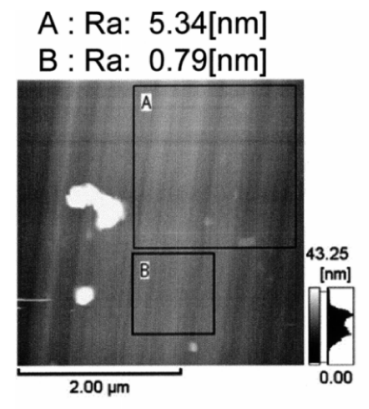

(a) as received

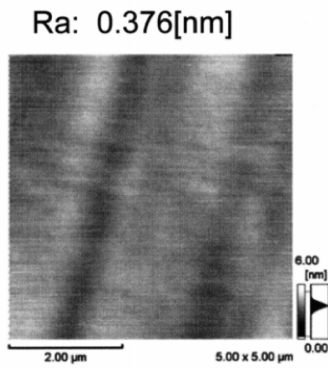

(b) Etched diamond surface
Ra: $0.358[\mathrm{~nm}]$

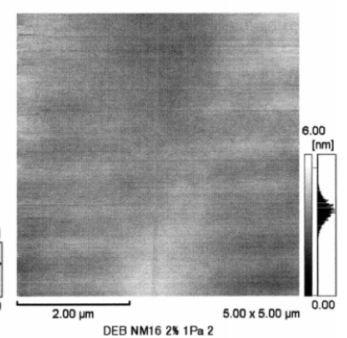

Figure 9: Reduction of surface roughness after $\mathrm{O}_{2} / \mathrm{CF}_{4}$ plasma observed with SEM. Taken from [28].

Alternatively, the preferred recipe to achieve this is to add argon to the oxygen based process. The etching mechanism is hereafter modified. Whereas pure oxygen results in a chemical etch, argon is used for physical etching (sputtering). 
Carbon atoms from the diamond are sputtered by the argon ions and react with $\mathrm{O}_{2}$ to form $\mathrm{CO}$ and $\mathrm{CO}_{2}$. The etching process is therefore less preferential and can produce a smoother surface than achieved with $\mathrm{O}_{2}$ and other gases. This gas combination used in an ICP RIE process offers better control of the etch process. [38]

Enlund et al. reported a very high etch rate of $0.22 \mu \mathrm{m} / \mathrm{min}$ and maintained a sample rms roughness of $3 \mathrm{~nm}$ (Figure 10). [39] Lee et al. achieved similar etch rates and rms roughness of 1-2 $\mathrm{nm}$. One sample however presented a roughness of $15 \mathrm{~nm}$, which they hypothesized was due to intrinsic defects in the particular HPHT-derived diamond. [38] Along similar lines, Maj et al. commented that $\mathrm{O}_{2} / \mathrm{Ar}$ is effective for small scale flattening but not to remove larger surface features. [40] As a result, the effectiveness of this etch recipe is likely to be very dependent on the pre-etch characteristics and roughness of the sample and undermined in the case of samples presenting significant surface features. Hicks et al. however observed that the addition of $\mathrm{Ar}$ to $\mathrm{O}_{2} / \mathrm{CF}_{4}$ removed the element of sample quality variation in achieved surface roughness, with near-zero etch pit formation on samples treated with the $\mathrm{Ar} / \mathrm{O}_{2} / \mathrm{CF}_{4}$ compared to $\mathrm{O}_{2} / \mathrm{CF}_{4}$. [41] Surface roughening was however observed on 3 of 7 processed samples. Atikian et al. also reported sample fracture during thick CVD growth following the use of an $\mathrm{O}_{2} / \mathrm{Ar}$ plasma etch. [42]

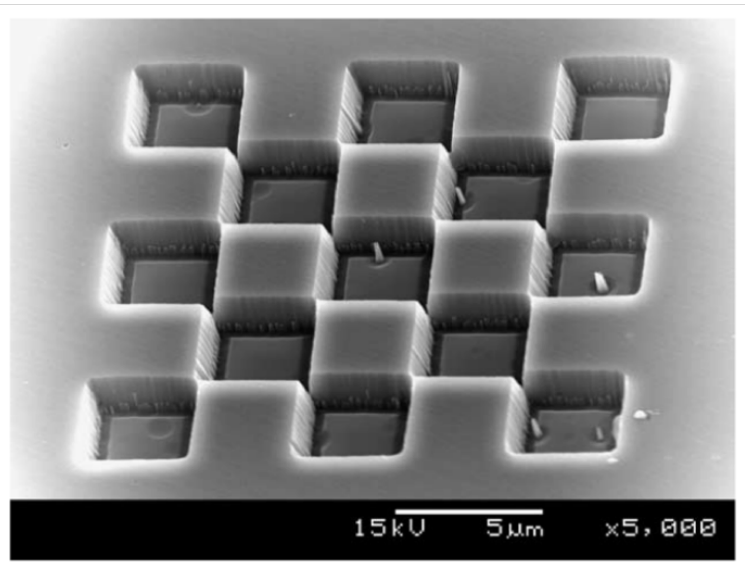

Figure 10: Smooth etched features in diamond after $\mathrm{Ar} / \mathrm{O}_{2}$ plasma etch (SEM). Taken from [39].

More recently Lee et al. have presented in [43] the use of an $\mathrm{Ar} / \mathrm{Cl}_{2}$ plasma for diamond etching. With an etch rate up to $0.1 \mu \mathrm{m} / \mathrm{min}$, they flatten the surface from an rms of $0.53 \mathrm{~nm}$ to $0.19 \mathrm{~nm}$ in 10 minutes (Figure 11. Birefringence microscopy illustrates the reduction in dislocation density and macroscopic surface features were not present after post-etch. Friel postulates that $\mathrm{Ar} / \mathrm{Cl}_{2}$ plasma does not etch damage sites preferentially like $\mathrm{O}_{2}$ plasmas do, resulting in the smoothing of the surface. [6] Muchnikov reported an increased etch rate 
up to $2 \mu \mathrm{m} / \mathrm{min}$ and maintained sample roughness around $1 \mathrm{~nm}$. More interestingly, their samples did not present visible defects after growth for substrates etched to a depth of more than $5 \mu \mathrm{m}$. [10], thus indicating the important role of etching away the outerlayer of a polished substrate by a well-chosen low damage RIE process prior to epitaxial growth. That this etch needs to be of the order of 5 microns or more, is consistent with the view that the mechanical polishing processes used to prepare diamond substrates impart high levels of sub-surface damage.
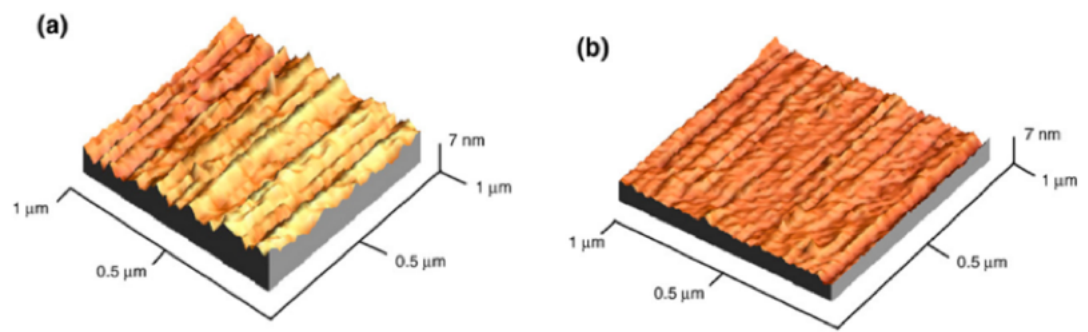

(c)

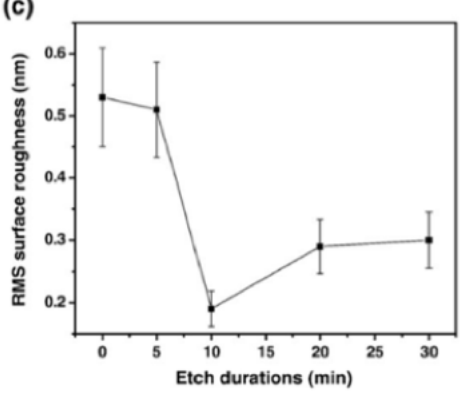

Figure 11: Smoothing effect of $\mathrm{Ar} / \mathrm{Cl}_{2}$ plasma on diamond, comparing the surface as-received (a), after 10 minute etch (b) and roughness for increasing etch duration (c). Taken from [43].

The best results for each combination of gases, when available, are presented in Table 1. The 'achieved roughness' or roughness achieved after plasma treatment is listed. It is important to note that the values are reported as rootmean-squared $\left(\mathrm{r}_{r m s}\right)$ or average roughness $\left(\mathrm{r}_{a}\right)$, offering an imperfect measure of comparison. $\mathrm{Ar} / \mathrm{O}_{2}$ and $\mathrm{CF}_{4} / \mathrm{O}_{2}$ plasmas offer minimal change in roughness whilst removing the damaged substrate surface. $\mathrm{Ar} / \mathrm{Cl}_{2}$ plasma shows the most promise in increasing the smoothness of the sample during the dry etch. These best measurements however were achieved on samples with very low roughness and at a comparably slow etch rate. Ar $/ \mathrm{O}_{2} / \mathrm{CF}_{4}$ also reduced roughness, however to a lesser extent and at a slower etch rate but on samples with a starting roughness more representative of commercially available and more commonly used diamond substrates.

The use of focused ion beam (FIB) tools is the other dry etching method 


\begin{tabular}{c|c|c|c} 
Plasma & $\begin{array}{c}\text { Etch Rate } \\
(\mu \mathrm{m} / \mathrm{h})\end{array}$ & $\begin{array}{c}\text { Achieved Roughness } \\
(\mathrm{nm})\end{array}$ & Roughness Change \\
\hline $\mathrm{Ar} / \mathrm{Cl}_{2}[43]$ & 6 & $0.19\left(\mathrm{r}_{r m s}\right)$ & $-64 \%$ \\
$\mathrm{CF}_{4} / \mathrm{O}_{2}[28]$ & 9.5 & $0.4\left(\mathrm{r}_{a}\right)$ & Decreased roughness \\
$\mathrm{H}_{2}[27]$ & 0.09 & $0.3-0.5\left(\mathrm{r}_{r m s}\right)$ & $+/-25 \%$ \\
$\mathrm{SF}_{6} / \mathrm{O}_{2}[22]$ & 16 & $20.2\left(\mathrm{r}_{a}\right)$ & $+42 \%$ \\
$\mathrm{Ar} / \mathrm{O}_{2}[39]$ & 13.2 & $3\left(\mathrm{r}_{r m s}\right)$ & No change \\
$\mathrm{Ar} / \mathrm{O}_{2} / \mathrm{CF}_{4}[41]$ & 3.6 & $1.6\left(\mathrm{r}_{a}\right)$ & $-44 \%$
\end{tabular}

Table 1: Best Reported Diamond Reactive Ion Etch Roughness Results

available to remove the substrate damage layer. High energy ions are implanted into the substrate to further damage the surface region. This makes the whole region highly disordered and prone to chemical etch during subsequent RIE or wet etch, enhancing the homogeneity of the etch process. The choice of ion is key to determine the depth of the induced damage, for example for oxygen ions the damage depth imparted by the incoming beam is around $500 \mathrm{~nm}$ compared to $46 \mathrm{~nm}$ when similar energy gallium ions are used [44, 45] FIB tools are, however, more generally used for direct milling to etch micro- and nano-scale features into diamond, rather than large area surface treatments, as it can be a time-consuming process to raster the tightly focused ion beam over large areas, often taking over 30 hours with the obvious cost and tool availability limitations that this implies. [46]

A slightly different approach to FIB, ion beam etching (IBE) utilises inert gas ions to physically sputter material from the surface over larger areas. [47, 48] Mi et al. showed that this approach offered the ability to smooth polishing scratches within 20 minutes of processing (Figure 12). Further characterisation of this process to determine its effect on sub-surface polishing damage and overall crystal quality on subsequently grown epitaxial layers would potential strengthen the case for its wider use.

Wet treatments with potassium based solutions can etch diamond through an oxidation process. Similar issues to those encountered with pure $\mathrm{O}_{2}$ plasma etching result, as etching is preferential and hence is not a viable option for substrate preparation. Wet etching is more commonly used to reveal defects in diamond. [40, 49-51]

Metal nanoparticles also have applications as catalysts for diamond plasma etching. Once on the surface of the diamond, enhanced etching will occur at the location of the metal nanoparticle in certain crystallographic directions. [52-54] Metal nanoparticles do not appear as the best solution for diamond substrate surface treatments, however they can be applied in other processes to reduce or exploit dislocation propagation at the substrate-epitaxial layer interface or produce features with specific crystalline surfaces. [8,55-58] Naanoum et al. have developed a method using Pt nanoparticles to block dislocations from propagating during epitaxial growth for improved crystal quality. [8] This treatment 
Figure 12: Reduction of a surface defect with IBE, from $108 \mathrm{~nm}$ to $8 \mathrm{~nm}$ depth in 20 minutes. Taken from [47].

achieved an etch pit density eight times lower after three CVD growths when compared to a reference sample.

A final method that has reportedly produced atomic flat diamond is known as 'dressed photon-phonon' or DPP etching, which is a form of photochemicaletching. Described in detail in [59], the authors developed a non-contact selforganized near-field etching procedure capable of producing atomically flat diamond. The process stops automatically once the surface is flat and the average roughness was reduced from $0.66 \mathrm{~nm}$ to $0.236 \mathrm{~nm}$ in one hour. For many applications, this process may be too slow and require a very low initial surface roughness on the substrate. However, it could be of interest to consider it as a final step smoothing if such extreme flatness is required for applications such a quantum information processing.

The surface treatment process that is chosen must address a number of issues such as: reduction of large scale features on the surface, small scale smoothing and sub-surface dislocation density reduction. Different etch recipes address different issues but none addresses all three. A suggestion would be to develop a cycle of treatment steps. Examples of such protocols are given in [37, 42, 60]. Yamada et al. have developed a two-step cycle etching diamond with an $\mathrm{O}_{2}$ plasma and removing SiN micro-masks with a $\mathrm{CF}_{4}$ plasma, attaining an average roughness smaller than $1 \mathrm{~nm}$. [37] In [60], a combination of $\mathrm{H}_{2} / \mathrm{O}_{2}$ plasma treatment, mechanical polishing and $\mathrm{O}_{2} / \mathrm{Ar}$ ICP RIE or chemo-mechanical polishing limited the propagation of dislocations during epitaxial growth. Such protocols have successfully reduced the surface roughness significantly, like in [42] from $30 \mathrm{~nm}$ to $150-300 \mathrm{pm}$ and demonstrate great promise for future use in substrate preparation. 

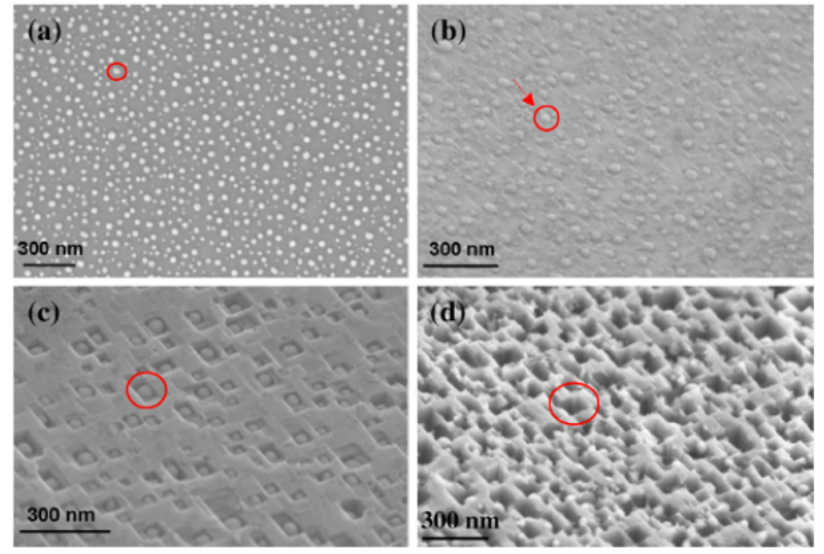

Figure 13: Catalytic etching of (100) polycrystalline diamond with Nickel nanoparticles. The diamond was etched in $\mathrm{H}_{2}$ for $30 \mathrm{~s} \mathrm{(a),} 3 \mathrm{~min}$ (b), $10 \mathrm{~min}$ (c) and $6 \mathrm{~h}(\mathrm{~d})$. Taken from [54].

A number of reported roughness values were described as corresponding to etch-pit free areas on a sample surface comprising such features. [27, 42] This observation, also seen in this work, highlights the inhomogeneity of the surface roughness on diamond substrates. This is an important factor to consider when fabricating devices as their location on smoother planes will be key to improving performance.

Further to this consideration, the available literature mostly only provides SEM, Atomic Force Microscopy (AFM) images and roughness measurements over limited areas to quantify the effects of the etch, partly because the literature does not address diamond etching for the sole purpose of surface treatment, often being applied to neeeds of lithography and patterning. This is rather insufficient for a proper evaluation and additional characterisation is necessary to qualify the subsurface damage, its removal and the improvement of the interface between the substrate and the epitaxially-grown layers to achieve high quality crystal growth.

\section{Characterisation Methods of Polishing Damage in Diamond}

Polishing induced mechanical damage in diamond remains challenging to characterise. The development of imaging techniques such as AFM and SEM have allowed the observation of the effects of polishing on diamond surfaces but to characterise sub-surface damage with these, destructive methods would be required. $[8,27,29,33,51]$ The use of non-destructive methods to quantify and qualify sub-surface damage in diamond substrates is not widely reported in the 
literature, although observations have been achieved with birefrigence imaging, X-ray topography and X-ray Diffraction. [6, 41]
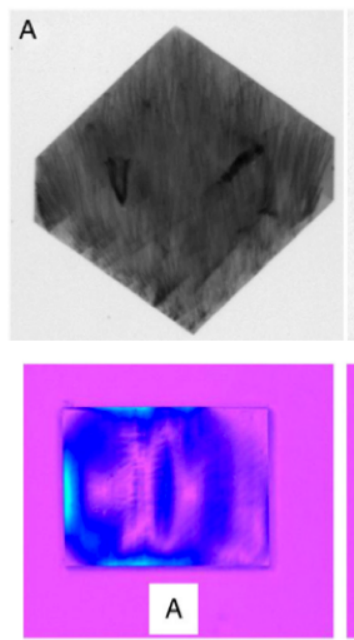

B
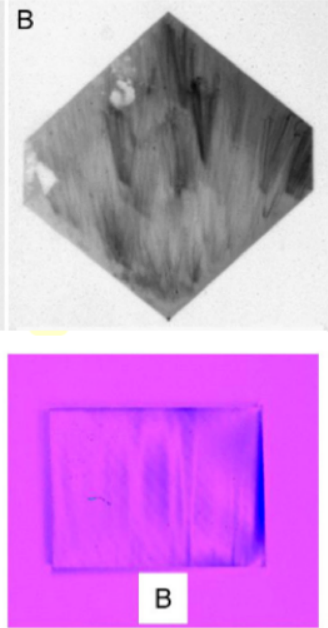

C
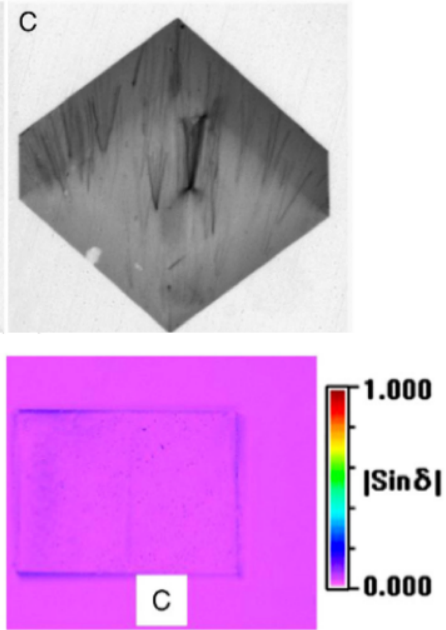

Figure 14: X-ray Topography (top) and birefringence (bottom) of samples with high (A), medium (M) and low (C) subsurface damage in diamond substrates. Light gray areas (top) or pink (bottom) are low defect areas, the dark or blue features are dislocations and defects in the crystal. Taken from [6].

The most commonly employed characterisation method for the assessment of polishing damage in diamond is the analysis of etch pit formation. Oxygen and hydrogen plasmas are known to preferentially etch defective diamond and therefore enlarge them to produce visible characteristic etch pits. The analysis of the density and morphology of the etch pits, imaged with AFM and SEM, can provide information on the nature of the defects and dislocation type as well as the degree of damage. It can, however, be challenging to differentiate between polishing-induced damage and bulk defects. This type of analysis has also been performed on grown epitaxial layers to compare the effects of different substrate quality on the quality of the epitaxial diamond. However, this method is highly destructive, once etched the sample is no longer usable for device fabrication due to the roughening of the surface detrimental to subsequent epitaxial growth. [61]

Alternatively, X-ray topography has been extensively used for the study of defects in diamond. With the benefit of being a non-destructive method, Xray topography produces images of the diffracted X-ray beam, highlighting any lattice irregularities produced by defects in the crystal. Predominantly applied to the study of bulk and growth defects in diamond, characteristic markings of mixed dislocations thought to result from polishing have however been observed 
and characterised. [62-66]
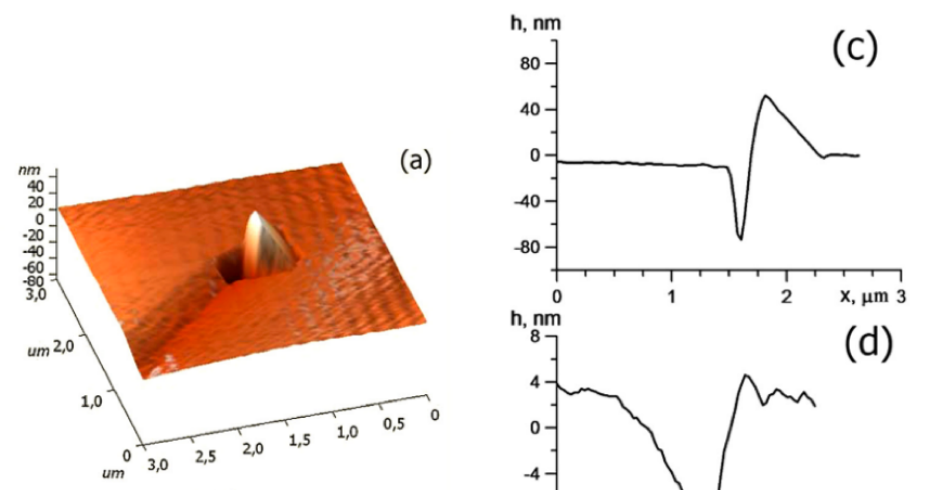

(b)
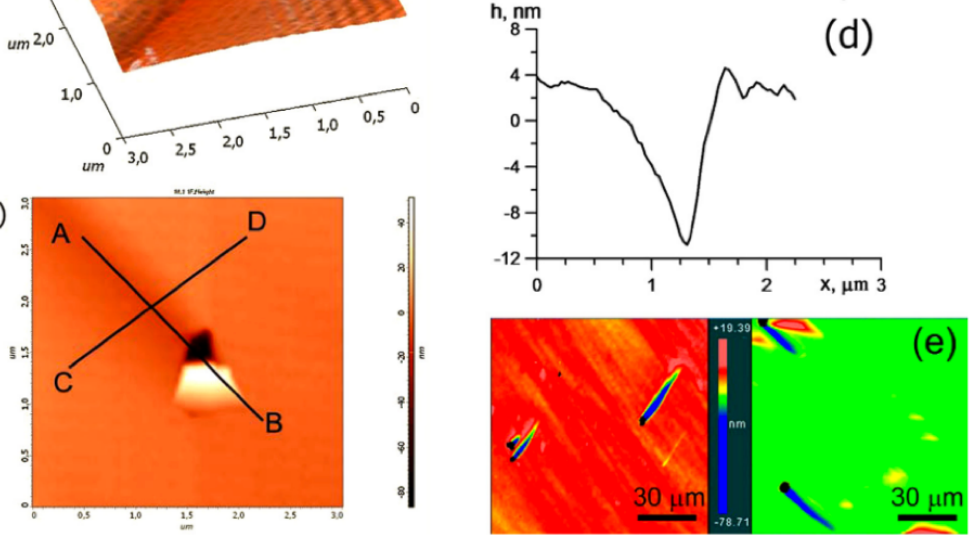

Figure 15: Comet-shaped defects after epitaxial growth of diamond for samples plasma-treated to etch depths less than $5 \mu \mathrm{m}$ observed with $3 \mathrm{D}$ AFM (a), 2D AFM (b) and corresponding line graphs AB (c) and CD (d), with larger view microscopy image (e). Taken from [10].

A small number of studies have used X-ray topography to specifically examine the effect of polishing on the quality of epitaxially-grown diamond. [6, 19] Friel et al. compared different polishes, known to have induced different levels of damage and observed a clear improvement in the crystalline quality of the diamond grown on less damaged and plasma surface treated substrates (Figure 14. [6] However, the observations are solely qualitative.

Likewise, birefrigence microscopy, cathodoluminescence and backscattered electron microscopy have been employed to image the localised deformation produced by bulk and sub-surface defects in diamond ((Figure 14). [9, 61, 62, 64, 67-70] Equally qualitative in their examination of the diamond samples, these microscopy techniques and X-ray topography do offer the potential of mapping defective areas prior to device fabrication and therefore can be used to correlate device performance to the presence or absence of observable growth and polishing defects.

The key information lacking with regards to the sub-surface damage induced during diamond polishing is the depth or extent of the damage, particulary in 
terms of its impact on electronic properties. The previously described characterisation methods offer two dimensional mapping of the defects. However, it is thought that the sub-surface polishing damage extends deep into the substrate, from hundreds of nanometers to ten microns from the surface, as mentioned above. $[6,9,10,71]$

Muchnikov et al. performed such a study, comparing the properties of different substrates after removing polished surface material. [10] Through the observation (or absence) of so-called "comets" (Figure 15), features in the polishing direction revealed after etch and CVD growth, they postulated different sub-surface damage depths for varying polish characteristics. They concluded that the depth of damage is highly dependent upon the polishing process and in some cases extends beyond $4 \mu \mathrm{m}$ depth. Hicks et al. iteratively examined a diamond substrate with High Resolution XRD after progressive etching with $\mathrm{Ar} / \mathrm{O}_{2} / \mathrm{CF}_{4}$ and observed a reduction in diffuse scattering after $6 \mu \mathrm{m}$ etch depth which they suggest corresponds to the onset of sub-surface damage removal and an estimate of sub-surface damage depth. [41] Understanding of the propagation depth of the polishing damage is particularly relevant to the development of pre-growth treatments to ensure removal of sufficient material to improve the quality of the subsequently grown layers and device performance. As noted in the introduction to this review, diamond polishing remains somewhat of an art form, and the polish quality is often highly dependant upon the experience of the person carrying out the procedure. By its very nature, this makes a systematic study and understanding of polish damage between different scientific groups and on diamond substrates of differing origins difficult.

\section{Patterning of Diamond with Reactive Ion Etching}

RIE is the standard technology employed by the semiconductor industry for device fabrication and patterning. Following a lithography process to produce a mask, the material can then be plasma etched to produce mesas. In terms of electronics, this allows the isolation of active layers from each other to structure a device.

In the case of diamond, similar processes to those described above for surface smoothing and pre-growth treatment are applied for patterning. Maintaining a smooth surface post-etch remains an important goal but the presence of a mask creates additional challenges to account for, namely selectivity, micro-masking, wall angle and quality control.

Diamond being such a hard material to chemically etch, the etch selectivity between commonly used masking materials and the diamond is significantly lower than that of other semiconducting materials. Silicon for example is readily etched with photoresist (polymeric) masks with selectivities of 150:1 [72] and deep etching is well understood and routinely performed to a high standard using the Bosch process. [73] In contrast, Lee et al. report selectivities of 0.098 and 0.057 for the resist SPR220 on diamond in $\mathrm{Ar} / \mathrm{O}_{2}$ and $\mathrm{Ar} / \mathrm{Cl}_{2}$ plasma respectively. [43] Photoresist masks are therefore rarely used for diamond pat- 
terning, except in cases of very shallow etching processes whereby a thick resist mask may last long enough for its purpose.

Metal, silicon dioxide and silicon nitride masks are more durable in a chemically aggressive plasma and can hence offer improved selectivity. Tran et al. compared a range of masking materials in $\mathrm{Ar} / \mathrm{O}_{2}$ and $\mathrm{Ar} / \mathrm{O}_{2} / \mathrm{SF}_{6}$ plasma, measuring the highest selectivity for Aluminium at 56. [36] Hwang et al. also found a selectivity of 50 for Aluminium in $\mathrm{Ar} / \mathrm{O}_{2}$. [23] Since the basis of most diamond RIE processes is the oxidation of the carbon with oxygen ions or radicals, a metal such as $\mathrm{Al}$ which forms a tenacious surface oxide protecting it from further erosion explains its use in this context. That said, the introduction of a physical component to the RIE process (such as the addition of Ar to the oxygen) will rapidly undermine the chemical etching resilience offered by the $\mathrm{Al}$ oxide layer.
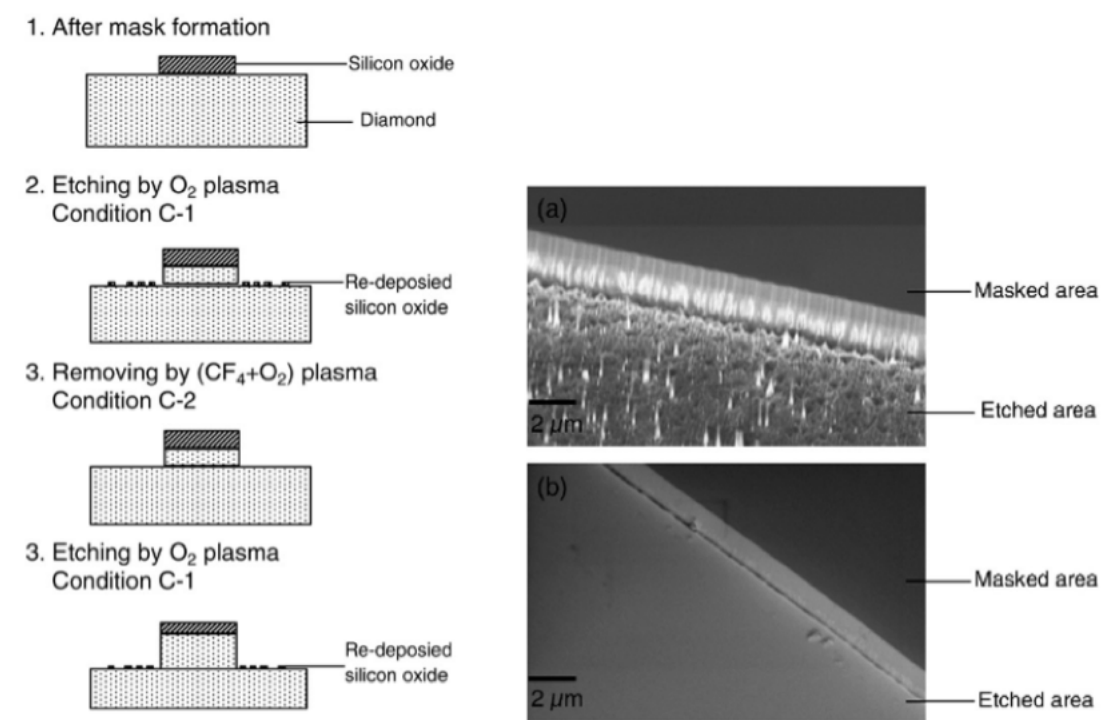

3. Removing by $\left(\mathrm{CF}_{4}+\mathrm{O}_{2}\right)$ plasma Condition C-2 
sample. The area is then masked by the particle and cannot be etched by the plasma. Pillars, often referred to as grass, are formed via this mechanism. Process engineering has to varying degrees minimised this effect, in particular through the addition of small amounts of fluorine-based gases to remove sputtered mask particles during the etch process (Figure 8) or the use of two step treatments (Figure 16). [22, 36, 37] The addition of fluorine-based gases to the plasma, however, reduces the selectivity of the etch. On the other hand, micromasking has been exploited to produce high aspect ratio features on diamond. [74-77]

The second challenge arising from the use of metal masks during diamond etching is mesa sidewall surface quality and angle control. As the etch proceeds, the mask sputters and redeposits onto the sidewall creating a protective layer. [78] This can significantly hinder the fabrication of vertical sidewalls as the progressive masking of sidewalls during the etch increases the angle away from vertical. Furthermore, the side morphology of the metal mask and re-deposition of metal on the mesa sidewalls produces rough and ridged sidewalls.

Plasma and mask morphology engineering is one possible solution to the control of sidewall angles. [23, 79, 80] Hwang et al. were able to utilise plasma and mask properties to produce a range of morphologies on diamond, including pyramids, needles and bottom-eroded cylinders. [23]

Another solution is the use of shadow hard masks (Figure 17). [81-84] When fabricating diamond membranes, diamond or glass pre-patterned hard masks are placed on the sample and provide an etch mask durable for long and deep etching $(\geq 100 \mu \mathrm{m})$, removing any potential effects from mask redeposition. Inhomogeneities in etch depth across the sample are however observed and sidewalls appear highly dependent on the nature of the shadow mask design. Alternatively, a successive iteration of etching and new mask deposition has been employed by Li et al. [85] Neither of these methods are convenient or suitable for multilayer devices which require accurate mask alignment.

A final trick developed to gain further control over the direction of the plasma ions and by consequence sidewall angle is the use of a Faraday cage (Figure 18). [86-88] The sample is placed inside a Faraday cage which has the effect of directing incoming ions following the angle of the Faraday cage grid. The angle of the etch is then highly controllable, although different Faraday cage designs are be required for any process variation.

With regards to achieving deep etch depths, beyond the $10 \mu \mathrm{m}$ mark, a few recent reports have shown promise for the future of diamond etching. Nagai et al. used the catalytic etching properties of nickel to produce $46 \mu \mathrm{m}$ wells with (111) faces and an atomically flat bottom. [58] This method is however restrictive in possible patterns due to the crystallographic nature of the process. Toros et al. achieved even deeper depths at $150 \mu \mathrm{m}$ to produce MEMS components using a high intensity oxygen plasma with a $7 \mu \mathrm{m} \mathrm{SiO}_{2}$ mask, with a thin aluminium layer to avoid mask delamination from the diamond. [89] They avoid micromasking despite the presence of silicon and achieve a 1:50 selectivity, but the surface roughness is near $200 \mathrm{~nm}$ which would not be smooth enough for application in electronics. 

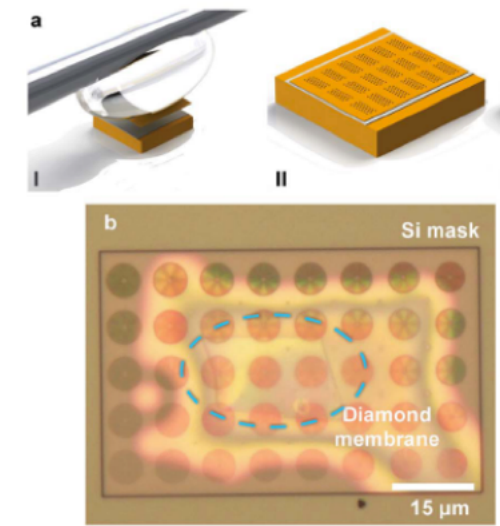
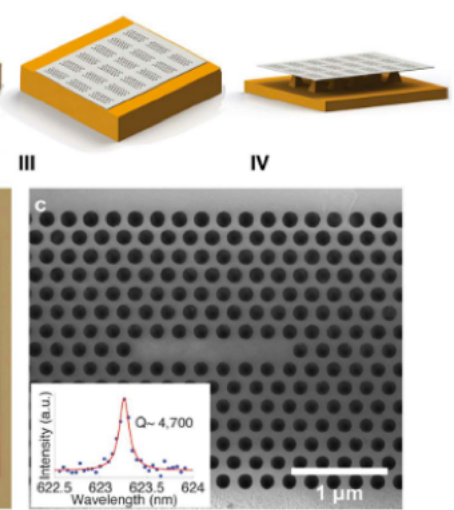

Figure 17: Example of the use of a silicon shadow mask to produce diamond lenses. Taken from [83].
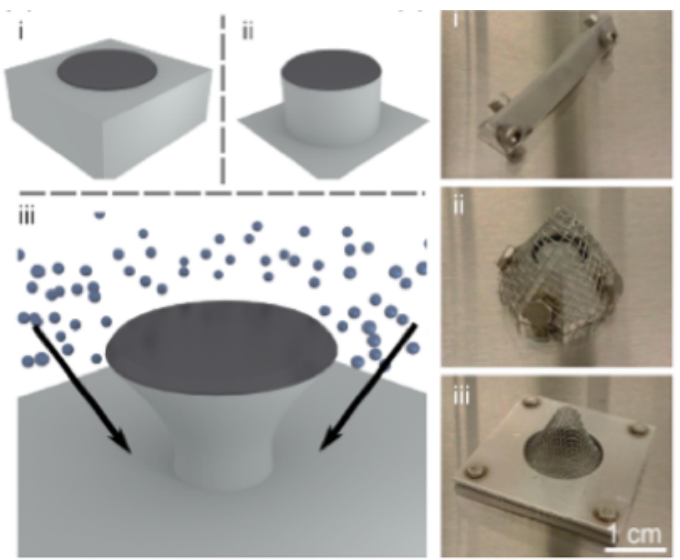

Figure 18: Example of the use of a Faraday cage for angled etching of diamond, with process diagrams on the left and example Faraday cage structures on the right. Taken from [87]. 
Most promising, Golovanov et al. produce $20 \mu \mathrm{m}$ in 6 hours with a $\mathrm{SF}_{6}$ plasma and nickel mask with selectivities up to 1:76. [80] They point to variation in selectivity related to the size of the features and don't observe any micromasking (Figure 19). It would be of significant interest to see this process applied to doped epitaxial diamond layers and understand if the process can be further improved to reduce trenching around features.

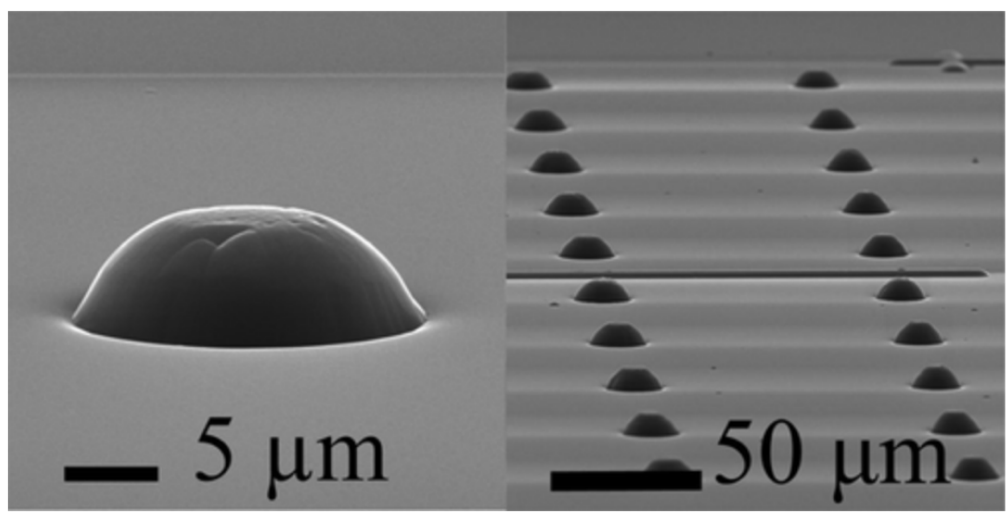

Figure 19: Diamond lenses fabricated by $160 \mathrm{~min} \mathrm{SF}_{6}$ plasma with nickel mask. Taken from [80].

A final consideration, little discussed to date in the literature is the effect of these plasma patterning processes on the diamond. Once the primary damage imparted by previous substrate polishing has been removed over the micron depth scale,it is important to consider what damage may be left behind, and over what depth scale, by the damage removing etch process itself. Kato et al. examined patterned diamond samples with X-ray Photoelectron Spectrocscopy and found that an ICP $\mathrm{O}_{2} / \mathrm{CF}_{4}$ process produced a $2 \mathrm{~nm}$ thick damage layer. [90] It was possible to reduce this damage to $1 \mathrm{~nm}$ with a less aggressive plasma and cleaning process to remove graphitic carbon. Such damage could be of crucial significance in electronic devices especially if the etched surface is directly involved in the active region of the electronic device being fabricated. It should, though, be noted that this is a problem encountered by the whole semiconductor industry and is not unique to diamond; the processes described above being capable, when used optimally, of offering diamond surfaces in a state close to that encountered with conventional materials.

\section{Conclusion}

Despite being the hardest material known and widely considered to be 'chemically inert', diamond can been etched and processed with a variety of methods as described in this review. The essential use of gas species resulting in a chemically and physically active plasma is one of the key requirements with regards 
to achieving a smooth diamond surface during plasma processing. It seems likely that the best etching protocols to be developed in the future will comprise several differing steps, perhaps cycled, to enable material removal at an acceptable rate, removal of surface and sub-surface damage, without its replacement with process damage, and the achievement of ultra-smooth final surfaces. Subtle process manipulation, such as the introduction within such a cycle of, say, fluorine-based gases are also needed to remove contaminant particles and micromasking that otherwise catastrophically undermine the etch process being developed.

Diamond pre-treatments to remove polishing damage and improve growth quality remain poorly characterised with no non-destructive quantitative studies, and few qualitative assessment and 'trial and error' analysis of the quality of the devices made on such surfaces following epitaxy. The depth and variability to which polishing damage extends in single crystal diamond requires to be better understood for future high performance device applications.

Finally, original methodologies for the patterning of diamond do enable the fabrication of a range of geometries, ranging from high aspect ratio features to undercuts and angled sidewalls. Limits on the fabrication process, however, remain with regards to depth achievable when more sophisticated devices are required comprising for multiple epitaxial layers, with few successful reports todate. The field of diamond etching has seen rapid development over the past few years, in part due to the improvements emerging in availale substrate materials. However, it is clear that further improvements in both substrate quality and diamond etching protocols are required for the realisation of device structures that could enter routine commercial use for a range of applications.

\section{Acknowledgements}

This work was performed as part of a European Commission project "GREENDIAMOND", H2020 Large Project (SEP-210184415). One of us (M-L. Hicks) thanks the UK's Engineering and Physical Research Council (EPSRC) for the award of a PhD studentship.

\section{References}

${ }^{1}$ R. Schirhagl, K. Chang, M. Loretz, and C. L. Degen, "Nitrogen-Vacancy Centers in Diamond: Nanoscale Sensors for Physics and Biology", Annual Review of Physical Chemistry 65, 83-105 (2014).

${ }^{2}$ L. Childress and R. Hanson, "Diamond NV centers for quantum computing and quantum networks", MRS Bulletin 38, 134-138 (2013).

${ }^{3}$ C. J. H. Wort and R. S. Balmer, "Diamond as an electronic material", Materials Today 11, 22-28 (2008).

${ }^{4} \mathrm{H}$. Umezawa, "Recent advances in diamond power semiconductor devices", Materials Science in Semiconductor Processing 78, 147-156 (2018). 
${ }^{5}$ P. A. Nistor, P. W. May, F. Tamagnini, A. D. Randall, and M. A. Caldwell, "Long-term culture of pluripotent stem-cell-derived human neurons on diamond - A substrate for neurodegeneration research and therapy", Biomaterials 61, 139-149 (2015).

${ }^{6}$ I. Friel, S. L. Clewes, H. K. Dhillon, N. Perkins, D. J. Twitchen, and G. A. Scarsbrook, "Control of surface and bulk crystalline quality in single crystal diamond grown by chemical vapour deposition", Diamond and Related Materials 18, 808-815 (2009).

${ }^{7}$ T. Schuelke and T. A. Grotjohn, "Diamond polishing", Diamond and Related Materials 32, 17-26 (2013).

${ }^{8}$ M. Naamoun, A. Tallaire, P. Doppelt, A. Gicquel, M. Legros, J. Barjon, and J. Achard, "Reduction of dislocation densities in single crystal CVD diamond by using self-assembled metallic masks", Diamond and Related Materials 58, 62-68 (2015).

${ }^{9}$ P. N. Volpe, P. Muret, F. Omnes, J. Achard, F. Silva, O. Brinza, and A. Gicquel, "Defect analysis and excitons diffusion in undoped homoepitaxial diamond films after polishing and oxygen plasma etching", Diamond and Related Materials 18, 1205-1210 (2009).

${ }^{10}$ A. B. Muchnikov, A. L. Vikharev, J. E. Butler, V. V. Chernov, V. A. Isaev, S. A. Bogdanov, A. I. Okhapkin, P. A. Yunin, and Y. N. Drozdov, "Homoepitaxial growth of CVD diamond after ICP pretreatment", Physica Status Solidi (A) Applications and Materials Science 212, 2572-2577 (2015).

${ }^{11}$ J. R. Hird and J. E. Field, "Diamond polishing", Proceedings of the Royal Society A: Mathematical, Physical and Engineering Sciences 460, 3547-3568 (2004).

${ }^{12} \mathrm{P}$. Grodzinski, Diamond Technology: Production Methods for Diamond and Gem Stones, 2nd Editio (N.A.G. Press, 1953).

${ }^{13}$ W. J. Zong, X. Cheng, and J. J. Zhang, "Atomistic origins of material removal rate anisotropy in mechanical polishing of diamond crystal", Carbon 99, 186194 (2016).

${ }^{14}$ E. L. H. Thomas, G. W. Nelson, S. Mandal, J. S. Foord, and O. A. Williams, "Chemical mechanical polishing of thin film diamond", Carbon 68, 473-479 (2014).

${ }^{15}$ N. Tatsumi, K. Harano, T. Ito, and H. Sumiya, "Polishing mechanism and surface damage analysis of type IIa single crystal diamond processed by mechanical and chemical polishing methods", Diamond \& Related Materials 63, 80-85 (2016).

${ }^{16}$ N. Tatsumi, K. Maruoka, K. Harano, T. Ito, and H. Sumiya, "Crystalline quality distributions of the type IIa diamond substrate and the CVD diamond layer processed by chemical mechanical polishing using a $\mathrm{SiO} 2$ wheel", Japanese Journal of Applied Physics 57 (2018). 
${ }^{17}$ Z. Yuan, Z. Jin, R. Kang, and Q. Wen, "Tribochemical polishing CVD diamond film with $\mathrm{FeNiCr}$ alloy polishing plate prepared by MA-HPS technique", Diamond and Related Materials 21, 50-57 (2012).

${ }^{18}$ J. Watanabe, M. Touge, and T. Sakamoto, "Ultraviolet-irradiated precision polishing of diamond and its related materials", Diamond and Related Materials 39, 14-19 (2013).

${ }^{19}$ Y. Kato, H. Umezawa, and S. I. Shikata, "X-Ray topographic study of a homoepitaxial diamond layer on an ultraviolet-irradiated precision polished substrate", Acta Physica Polonica A 125, 969-971 (2014).

${ }^{20}$ K. Nojiri, Dry Etching Technology for Semiconductors (Springer, 2015).

${ }^{21}$ T. Izak, A. Kromka, O. Babchenko, M. Ledinsky, K. Hruska, and E. Verveniotis, "Comparative study on dry etching of polycrystalline diamond thin films", Vacuum 86, 799-802 (2012).

${ }^{22}$ D. T. Tran, T. A. Grotjohn, D. K. Reinhard, and J. Asmussen, "Microwave plasma-assisted etching of diamond", Diamond and Related Materials 17, 717-721 (2008).

${ }^{23}$ D. S. Hwang, T. Saito, and N. Fujimori, "New etching process for device fabrication using diamond", Diamond and Related Materials 13, 2207-2210 (2004).

${ }^{24} \mathrm{R}$. Otterbach and U. Hilleringmann, "Reactive ion etching of CVD-diamond for piezoresistive pressure sensors", Diamond and Related Materials 11, 841844 (2002).

${ }^{25}$ B. J. M. Hausmann, M. Khan, Y. Zhang, T. M. Babinec, K. Martinick, M. McCutcheon, P. R. Hemmer, and M. Lončar, "Fabrication of diamond nanowires for quantum information processing applications", Diamond and Related Materials 19, 621-629 (2010).

${ }^{26}$ R. Ramesham, W. Welch, W. Neely, M. Rose, and R. Askew, "Plasma etching and patterning of CVD diamond at $<100 \mathrm{C}$ for microelectronics applications", Thin Solid Films 304, 245-251 (1997).

${ }^{27}$ O. Ivanov, A. Muchnikov, V. Chernov, S. Bogdanov, A. Vikharev, and J. Butler, "Experimental study of hydrogen plasma etching of (100) single crystal diamond in a MPACVD reactor", Materials Letters 151, 115-118 (2015).

${ }^{28}$ Y. Ando, Y. Nishibayashi, K. Kobashi, T. Hirao, and K. Oura, "Smooth and high-rate reactive ion etching of diamond", Diamond and Related Materials 11, 824-827 (2002).

${ }^{29}$ N. Tsubouchi, Y. Mokuno, and S. Shikata, "Characterizations of etch pits formed on single crystal diamond surface using oxygen/hydrogen plasma surface treatment", Diamond and Related Materials 63, 43-46 (2016).

${ }^{30}$ G. Bogdan, M. Nesládek, J. D. Haen, J. Maes, V. V. Moshchalkov, K. Haenen, and M. D\&apos;Olieslaeger, "Growth and characterization of near-atomically flat, thick homoepitaxial CVD diamond films", Physica Status Solidi (A) Applications and Materials Science 202, 2066-2072 (2005). 
${ }^{31}$ L. M. Yang, J. H. Gong, Z. M. Yue, S. N. Liu, Q. L. Chen, and J. Gao, "Preferential Etching by Flowing Oxygen on the $\{100\}$ Surfaces of HPHT Single Crystal Diamond 1", Journal of Superhard Materials 39, 18-24 (2017).

${ }^{32}$ N. Tsubouchi, Y. Mokuno, and S. Shikata, "Characterizations of etch pits formed on single crystal diamond surface using oxygen / hydrogen plasma surface treatment", Diamond \& Related Materials 63, 43-46 (2016).

${ }^{33}$ J. Achard, F. Silva, O. Brinza, X. Bonnin, V. Mille, R. Issaoui, M. Kasu, and A. Gicquel, "Identification of etch-pit crystallographic faces induced on diamond surface by H 2/O 2 etching plasma treatment", Physica Status Solidi (A) Applications and Materials Science 206, 1949-1954 (2009).

${ }^{34}$ C. D. McGray, R. A. Allen, M. Cangemi, and J. Geist, "Rectangular scalesimilar etch pits in monocrystalline diamond", Diamond and Related Materials 20, 1363-1365 (2011).

${ }^{35}$ M. Kiss, T. Graziosi, A. Toros, T. Scharf, O. J. F. Martin, and N. Quack, "Characterization of crystallographically etched single crystal diamond diffraction gratings", in 2018 international conference on optical mems and nanophotonics (omn) (2018).

${ }^{36}$ D. T. Tran, C. Fansler, T. A. Grotjohn, D. K. Reinhard, and J. Asmussen, "Investigation of mask selectivities and diamond etching using microwave plasmaassisted etching", Diamond and Related Materials 19, 778-782 (2010).

${ }^{37}$ T. Yamada, H. Yoshikawa, H. Uetsuka, S. Kumaragurubaran, N. Tokuda, and S. ichi Shikata, "Cycle of two-step etching process using ICP for diamond MEMS applications", Diamond and Related Materials 16, 996-999 (2007).

${ }^{38}$ C. L. Lee, H. W. Choi, E. Gu, M. D. Dawson, and H. Murphy, "Fabrication and characterization of diamond micro-optics", Diamond and Related Materials 15, 725-728 (2006).

${ }^{39}$ J. Enlund, J. Isberg, M. Karlsson, F. Nikolajeff, J. Olsson, and D. J. Twitchen, "Anisotropic dry etching of boron doped single crystal CVD diamond", Carbon 43, 1839-1842 (2005).

${ }^{40}$ J. A. Maj, A. T. Macrander, G. J. Waldschmidt, S. F. Krasnicki, Y. Zhong, R. Khachatryan, Y. S. Chu, R. Erck, and J. Woodford, "Etching Methods for Improving Surface Imperfections of Diamonds Used for X-Ray Monochromators", in Denver x-ray conference on applications of X-ray analysis ().

${ }^{41}$ M.-L. Hicks, A. C. Pakpour-Tabrizi, V. Zuerbig, L. Kirste, C. Nebel, and R. B. Jackman, "Optimisation of Smoothing Diamond Surface Treatment for Polishing Damage Removal", Submitted for Publication (2019).

${ }^{42}$ H. A. Atikian, A. Eftekharian, A. Jafari Salim, M. J. Burek, J. T. Choy, A. Hamed Majedi, and M. Lončar, "Superconducting nanowire single photon detector on diamond", Applied Physics Letters 104, 1-5 (2014).

${ }^{43}$ C. L. Lee, E. Gu, M. D. Dawson, I. Friel, and G. A. Scarsbrook, "Etching and micro-optics fabrication in diamond using chlorine-based inductively-coupled plasma", Diamond and Related Materials 17, 1292-1296 (2008). 
${ }^{44}$ A. A. Martin, S. Randolph, A. Botman, M. Toth, and I. Aharonovich, "Maskless milling of diamond by a focused oxygen ion beam", Scientific Reports 5, 8958 (2015).

${ }^{45}$ I. Bayn, A. Bolker, C. Cytermann, B. Meyler, V. Richter, J. Salzman, and R. Kalish, "Diamond processing by focused ion beam-surface damage and recovery", Applied Physics Letters 99 (2011) 10.1063/1.3658631.

${ }^{46}$ O. Dyachenko, N. Diek, Y. Shapiro, R. Tamang, W. Harneit, M. Reichling, and A. Borodin, "A diamond (1 00 ) surface with perfect phase purity", Chemical Physics Letters 640, 72-76 (2015).

${ }^{47} \mathrm{~S}$. Mi, A. Toros, T. Graziosi, and N. Quack, "Non-contact polishing of single crystal diamond by ion beam etching", Diamond \& Related Materials 92, 248-252 (2019).

${ }^{48}$ A. E. Ieshkin, K. D. Kushkina, D. S. Kireev, Y. A. Ermakov, and V. S. Chernysh, "Polishing Superhard Material Surfaces with Gas-Cluster Ion Beams", Technical Physics Letters 43, 95-97 (2017).

${ }^{49}$ F. K. De-Theije, E. Van-Veenendaal, W. J. P. Van-Enckevort, and E. Vlieg, "Oxidative etching of cleaved synthetic diamond $\{111\}$ surfaces", Surface Science 492, 91-105 (2001).

${ }^{50}$ F. K. De Theije, O. Roy, N. J. Van Der Laag, and W. J. P. Van Enckevort, "Oxidative etching of diamond", Diamond and Related Materials 9, 929-934 (2000).

${ }^{51}$ A. F. Khokhryakov and Y. N. Palyanov, "Revealing of dislocations in diamond crystals by the selective etching method", Journal of Crystal Growth 293, 469-474 (2006).

${ }^{52}$ T. Ohashi, W. Sugimoto, and Y. Takasu, "Catalytic etching of $\{100\}$-oriented diamond coating with $\mathrm{Fe}, \mathrm{Co}, \mathrm{Ni}$, and Pt nanoparticles under hydrogen", Diamond and Related Materials 20, 1165-1170 (2011).

${ }^{53}$ T. Ohashi, W. Sugimoto, and Y. Takasu, "Catalytic roughening of surface layers of BDD for various applications", Electrochimica Acta 54, 5223-5229 (2009).

${ }^{54}$ H. A. Mehedi, J. C. Arnault, D. Eon, C. Hébert, D. Carole, F. Omnes, and E. Gheeraert, "Etching mechanism of diamond by Ni nanoparticles for fabrication of nanopores", Carbon 59, 448-456 (2013).

${ }^{55}$ K. Nakanishi, H. Kuroshima, T. Matsumoto, T. Inokuma, and N. Tokuda, "Atomically flat diamond ( 100 ) surface formation by anisotropic etching of solid-solution reaction of carbon into nickel", Diamond \& Related Materials 68, 127-130 (2016).

${ }^{56}$ Y. Morofushi, H. Matsushita, and N. Miki, "Microscale patterning of single crystal diamond by thermochemical reaction between sidero-metal and diamond", Precision Engineering 35, 490-495 (2011). 
${ }^{57}$ K. Liu, Z. Lv, B. Dai, G. Shu, J. Zhao, B. Liu, and W. Wang, "High-selectivity anisotropic etching of single-crystal diamond by $\mathrm{H}$ plasma using iron catalysis", Diamond \& Related Materials 86, 186-192 (2018).

${ }^{58}$ M. Nagai, K. Nakanishi, H. Takahashi, and H. Kato, "Anisotropic diamond etching through thermochemical reaction between $\mathrm{Ni}$ and diamond in hightemperature water vapour", Scientific Reports, 1-8 (2018).

${ }^{59}$ T. Yatsui, W. Nomura, M. Naruse, and M. Ohtsu, "Realization of an atomically flat surface of diamond using dressed photon-phonon etching", Journal of Physics D: Applied Physics 45, 475302 (2012).

${ }^{60}$ J. Achard, A. Tallaire, V. Mille, M. Naamoun, O. Brinza, A. Boussadi, L. William, and A. Gicquel, "Improvement of dislocation density in thick CVD single crystal diamond films by coupling $\mathrm{H} 2 / \mathrm{O} 2$ plasma etching and chemomechanical or ICP treatment of HPHT substrates", Physica Status Solidi (A) Applications and Materials Science 211, 2264-2267 (2014).

${ }^{61}$ A. Tallaire, J. Barjon, O. Brinza, J. Achard, F. Silva, V. Mille, R. Issaoui, A. Tardieu, and A. Gicquel, "Dislocations and impurities introduced from etchpits at the epitaxial growth resumption of diamond", Diamond and Related Materials 20, 875-881 (2011).

${ }^{62}$ H. Umezawa, Y. Kato, H. Watanabe, A. M. M. Omer, H. Yamaguchi, and S. I. Shikata, "Characterization of crystallographic defects in homoepitaxial diamond films by synchrotron X-ray topography and cathodoluminescence", Diamond and Related Materials 20, 523-526 (2011).

${ }^{63}$ C. K. Suzuki, A. H. Shinohara, P. H. Godoy, N. Watanabe, and M. Kamo, "Xray topographic characterization of epitaxially grown diamond film", Diamond and Related Materials 7, 289-292 (1998).

${ }^{64}$ G. S. Woods and A. R. Lang, "Cathodoluminescence, optical absorption and X-ray topographic studies of synthetic diamonds", Journal of Crystal Growth 28, 215-226 (1975).

${ }^{65}$ S. Masuya, K. Hanada, T. Oshima, H. Sumiya, and M. Kasu, "Formation of stacking fault and dislocation behavior during the high-temperature annealing of single-crystal HPHT diamond", Diamond and Related Materials 75, 155160 (2017).

${ }^{66}$ M. P. Gaukroger, P. M. Martineau, M. J. Crowder, I. Friel, S. D. Williams, and D. J. Twitchen, "X-ray topography studies of dislocations in single crystal CVD diamond", Diamond and Related Materials 17, 262-269 (2008).

${ }^{67}$ H. Jasbeer, R. J. Williams, O. Kitzler, A. McKay, S. Sarang, J. Lin, and R. P. Mildren, "Birefringence and piezo-Raman analysis of single crystal CVD diamond and effects on Raman laser performance", Journal of the Optical Society of America B 33, 56-64 (2016).

${ }^{68}$ L. T. M. Hoa, T. Ouisse, D. Chaussende, M. Naamoun, A. Tallaire, and J. Achard, "Birefringence microscopy of unit dislocations in diamond", Crystal Growth and Design 14, 5761-5766 (2014). 
${ }^{69}$ E. V. Korostylev, V. S. Bormashov, S. A. Tarelkin, and M. A. Doronin, "Using electron backscatter diffraction to investigate the influence of mechanical polishing on the state of the surface of diamond", Journal of Surface Investigation: X-ray, Synchrotron and Neutron Techniques 11, 125-129 (2017).

${ }^{70}$ A. Tallaire, V. Mille, O. Brinza, T. N. Tran Thi, J. Brom, Y. Loguinov, A. Katrusha, A. Koliadin, and J. Achard, "Thick CVD diamond films grown on high-quality type IIa HPHT diamond substrates from New Diamond Technology", Diamond and Related Materials 77, 146-152 (2017).

${ }^{71}$ M. Naamoun, A. Tallaire, F. Silva, J. Achard, P. Doppelt, and A. Gicquel, "Etch-pit formation mechanism induced on HPHT and CVD diamond single crystals by $\mathrm{H} 2 / \mathrm{O} 2$ plasma etching treatment: Part of topical section on fundamentals and applications of diamond", Physica Status Solidi (A) Applications and Materials Science 209, 1715-1720 (2012).

${ }^{72}$ A. M. Hynes, H. Ashraf, J. K. Bhardwaj, J. Hopkins, I. Johnston, and J. N. Shepherd, "Recent advances in silicon etching for MEMS using the ASEe process", 13-17 (1999).

${ }^{73}$ F. Laermer and A. Schilp, Method of anisotropically etching silicon, 1996.

${ }^{74}$ B. Hausmann, M. Khan, T. Babinec, Y. Zhang, K. Martinick, M. McCutcheon, P. Hemmer, and M. Loncar, "Fabrication of Diamond Nanowires for Quantum Information Processing Applications", (2009) 10.1016/j.diamond.2010.01. 011.

${ }^{75}$ P. Subramanian, S. Kolagatla, S. Szunerits, Y. Coffinier, W. S. Yeap, K. Haenen, R. Boukherroub, and A. Schechter, "Atomic Force Microscopic and Raman Investigation of Boron-Doped Diamond Nanowire Electrodes and Their Activity toward Oxygen Reduction", The Journal of Physical Chemistry C, acs.jpcc.6b11546 (2017).

${ }^{76}$ M. L. Terranova, S. Orlanducci, M. Rossi, and E. Tamburri, "Nanodiamonds for field emission: state of the art.", Nanoscale 7, 5094-114 (2015).

${ }^{77} \mathrm{~N}$. Yang, W. Zong, Z. Li, and T. Sun, "Wear process of single crystal diamond affected by sliding velocity and contact pressure in mechanical polishing", Diamond \& Related Materials 58, 46-53 (2015).

${ }^{78}$ E. Vargas Catalan, P. Forsberg, O. Absil, and M. Karlsson, "Controlling the profile of high aspect ratio gratings in diamond", Diamond and Related Materials 63, 60-68 (2016).

${ }^{79}$ M. Mitchell, D. P. Lake, and P. E. Barclay, "Realizing Q > 300000 in diamond microdisks for optomechanics via etch optimization", APL Photonics 4 (2019) $10.1063 / 1.5053122$

${ }^{80}$ A. V. Golovanov, V. S. Bormashov, N. V. Luparev, S. A. Tarelkin, S. Y. Troschiev, S. G. Buga, and V. D. Blank, "Diamond Microstructuring by Deep Anisotropic Reactive Ion Etching", Physica Status Solidi (A) Applications and Materials Science 215, 1800273 (2018). 
${ }^{81}$ J. Kleinlein, T. Borzenko, F. Munzhuber, J. Brehm, T. Kiessling, and L. W. Molenkamp, "NV-center diamond cantilevers: Extending the range of available fabrication methods", Microelectronic Engineering 159, 70-74 (2016).

${ }^{82}$ P. Appel, E. Neu, M. Ganzhorn, A. Barfuss, M. Batzer, M. Gratz, A. Tschöpe, and P. Maletinsky, "Fabrication of all diamond scanning probes for nanoscale magnetometry", Review of Scientific Instruments 87 (2016) 10.1063/1. 4952953.

${ }^{83}$ L. Li, I. Bayn, M. Lu, C.-Y. Nam, T. Schröder, A. Stein, N. C. Harris, and D. Englund, "Nanofabrication on unconventional substrates using transferred hard masks", Scientific Reports 5, 7802 (2015).

${ }^{84}$ S. Ali Momenzadeh, F. F. De Oliveira, P. Neumann, D. D. Bhaktavatsala Rao, A. Denisenko, M. Amjadi, Z. Chu, S. Yang, N. B. Manson, M. W. Doherty, and J. Wrachtrup, "Thin Circular Diamond Membrane with Embedded NitrogenVacancy Centers for Hybrid Spin-Mechanical Quantum Systems", Physical Review Applied 6, 1-9 (2016).

${ }^{85}$ L. Li, M. Trusheim, O. Gaathon, K. Kisslinger, C.-J. Cheng, M. Lu, D. Su, X. Yao, H.-C. Huang, I. Bayn, A. Wolcott, R. M. Osgood, and D. Englund, "Reactive ion etching: Optimized diamond membrane fabrication for transmission electron microscopy", Journal of Vacuum Science \& Technology B: Microelectronics and Nanometer Structures 31, 06FF01 (2013).

${ }^{86}$ M. J. Burek, Y. Chu, M. S. Z. Liddy, P. Patel, J. Rochman, S. Meesala, W. Hong, Q. Quan, M. D. Lukin, and M. Lončar, "High quality-factor optical nanocavities in bulk single-crystal diamond", Nature Communications 5, 5718 (2014).

${ }^{87}$ P. Latawiec, M. J. Burek, Y.-I. Sohn, and M. Lončar, "Faraday cage angledetching of nanostructures in bulk dielectrics", J. Vac. Sci. Technol. B 34, 041801 (2016).

${ }^{88}$ S.-w. Cho, J.-h. Kim, W. Kang, K. Lee, and C.-k. Kim, "Single- and MultiDirectional Slanted Plasma Etching of Silicon under Practical Plasma Processing Conditions", 3 (2014) 10.1149/2.0091411jss.

${ }^{89}$ A. Toros, M. Kiss, T. Graziosi, H. Sattari, P. Gallo, and N. Quack, "Precision micro-mechanical components in single crystal diamond by deep reactive ion etching", Microsystems \& Nanoengineering (2018) 10.1038/s41378-0180014-5.

${ }^{90}$ Y. Kato, H. Kawashima, T. Makino, and M. Ogura, "Estimation of Inductively Coupled Plasma Etching Damage of Boron-Doped Diamond Using XRay Photoelectron Spectroscopy", Physica Status Solidi (A) Applications and Materials Science 214, 1700233 (2017). 